\title{
advances
}

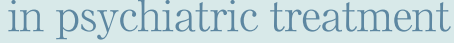

\section{CPD Online}

241 New from CPD Online

\section{Articles}

242 New diagnostic concepts in Alzheimer's disease

Anna Watkin, Sudip Sikdar, Biswadeep Majumdar \& Anna V. Richman

250 Lost in translation: transferring knowledge from research

to clinical practice

John Wallace

259 Boredom among psychiatric in-patients: does it matter?

Rachel Steele, Paul Henderson, Frances Lennon \& Donna Swinden

268 What civilian psychiatrists should know about military psychiatry Martin Deahl \& Rehan Siddiquee

276 Suicide mitigation: a compassionate approach to suicide prevention Alys Cole-King, Gill Green, Linda Gask, Kevin Hines \& Stephen Platt

284 Suicide prevention: are we doing enough? Alys Cole-King, Victoria Parker, Helen Williams \& Stephen Platt

292 Hey kid, are you OK? A story of suicide survived Kevin Hines, Alys Cole-King \& Mel Blaustein

295 To be or not to be: legal and ethical considerations in suicide prevention Jaydip Sarkar

302 Review of treatment for late-life depression Charlotte L. Allan \& Klaus P. Ebmeier

310 Supportive psychodynamic psychotherapy for psychosis Bent Rosenbaum, Brian Martindale \& Alison Summers

\section{Cover image}

Boredom is not trivial matter for psychiatric in-patients. In this

issue, Steele et al (pp. 259-267) consider in-patients' experience of boredom, the contribution of medication and ways of alleviating boredom on wards Image: (C) iStockphoto/Alina Pavlova. 